\title{
A tutela do meio ambiente sob a ótica do Tribunal de Justiça de Minas Gerais
}

A evolução social cumulada às complexas e crescentes necessidades da raça humana acabam por elevar de forma cada vez mais significativa a exploração ao meio ambiente onde está inserida. Surge então o Direito Ambiental, composto por princípios e regras, como instrumento regulador da atuação humana sobre o meio ambiente. O trabalho analisa a atuação do TJMG - Tribunal de Justiça de Minas Gerais - no âmbito do Direito Ambiental, como foco na aplicação do panorama princípio lógico em seus julgamentos, para verificar os valores mais presentes na jurisprudência do Tribunal Mineiro. A pesquisa utilizou o sistema de busca jurisprudencial disponível no site virtual do TJMG, que permite ampla filtragem e estabelecimento de critérios de busca. Cada princípio reconhecido pela doutrin foi pesquisado de maneira isolada para verificação quantitativa de sua menção pelo TJMG nos últimos cinco anos (2014, 2015, 2016, 2017 e 2018). No total os princípios foram citados em 3014 vezes, sendo o 'meio ambiente ecologicamente equilibrado' o mais mencionado (1290 citações), seguido pelos princípios da 'prevenção' (533 citações), da 'precaução' (353 citações), do 'desenvolvimento sustentável' (302 citações) e do 'poluidor-pagador' (287 citações). Lado outro, alguns princípios não foram mencionados pelo Tribunal, como o do 'protetor-recebedor' e o da 'consideração da variável ambiental no processo decisório de políticas de desenvolvimento'. De 2014 a 2018 houve aumento de 14,07\% na citação a princípios ambientais pelo TJMG (540 em $2014 ; 616$ em 2018 ), sendo 2017 o ano de maior presença princípio lógica nos julgamentos (656 citações), seguido por 2016 (643 citações), e 2018 (616 citações).

Palavras-chave: Direito Ambiental; Princípios; Jurisprudência.

\section{The protection of the environment from the perspective of the Court of Justice of Minas Gerais}

\begin{abstract}
The social evolution cumulated to the complex and growing needs of the human race end up increasing in an increasingly significant way the exploration to the environment where it is inserted. Environmental Law, consisting of principles and rules, emerges as a regulatory instrument of human action on the environment. The paper analyzes the performance of the TJMG - Court of Justice of Minas Gerais - in the ambit of Environmental Law, as a focus on the application of the principiological panorama in its judgments, to verify the most present values in the jurisprudence of the Mining Court. The research used the jurisprudential search system available on the TJMG's virtual site, which allows extensive filtering and establishment of search criteria. Each principle recognized by the doctrine was searched in isolation for quantitative verification of its mention by the TJMG in the last five years $(2014,2015,2016,2017$ and 2018$)$. In all, the principles were cited in 3014 times, the 'environmentally balanced environment' being the most mentioned (1290 citations), followed by the principles of 'prevention' (533 citations), 'precaution' (353 citations), 'development sustainable '(302 citations) and the' polluter pays' (287 citations). On the other hand, some principles were not mentioned by the Court, such as the 'protector-recipient' and the 'consideration of the environmental variable in the development policy decision-making process'. From 2014 to 2018 there was a $14.07 \%$ increase in the citation to environmental principles by the TJMG (540 in 2014, 616 in 2018), with 2017 being the year with the highest princiological presence in the trials (656 citations), followed by 2016 (643 citations), and 2018 (616 citations)
\end{abstract}

Keywords: Environmental Law; Principles; Jurisprudence.

Topic: Legislação e Direito Ambiental

Reviewed anonymously in the process of blind peer.
Received: $17 / 03 / 2020$

Approved: 11/04/2020
Diego Fillipe Otoni de Barros Castro (iD)

Faculdade de Ipatinga, Brasil

http://lattes.cnpq.br/4390733020598094

http://orcid.org/0000-0002-1228-996X

dcastnnp@yahoo.com.br

Jonathan Willian Zangeski Novais (it

Universidade de Cuiabá, Brasil

http://lattes.cnpq.br/5665663207008673

http://orcid.org/0000-0002-6598-3138

jonathan.novais@kroton.com.br

Frederico Corrêa Campos (iD

Faculdade Pitágoras de Ipatinga, Brasil

http://lattes.cnpq.br/7064985413610046

http://orcid.org/0000-0003-3435-8062

fredericocorreacampos@gmail.com
Bruno Campos Morato

Faculdade Pitágoras de Ipatinga, Brasil http://lattes.cnpq.br/5400091904855675

http://orcid.org/0000-0003-2558-819X

brunobio10@gmail.com

Naara Soares dos Santos Brito

Universidade de Cuiabá, Brasil

http://lattes.cnpq.br/4674168290044825

http://orcid.org/0000-0002-1355-7102

naara6561@gmail.com

\section{Referencing this:}

CASTRO, D. F. O. B.; NOVAIS, J. W. Z.; CAMPOS, F. C.; MORATO, B. C.; BRITO, N. S. S.. A tutela do meio ambiente sob a ótica do Tribunal de Justiça de Minas Gerais. Nature and Conservation, v.13, n.2, p.94-107, 2020. DOI: http://doi.org/10.6008/CBPC2318-2881.2020.002.0010 


\section{INTRODUÇÃO}

O passar do tempo e cada vez mais célere avanço da sociedade trazem consigo diversas consequências, em especial transformação ambiental promovida pelo ser humano para o suprimento de suas complexas necessidades. O meio ambiente tem sido objeto agressões das mais diversas ordens, como a exploração para a subsistência, a transformação do ambiente natural em artificial em decorrência da formação das sociedades, a emissão de poluentes em decorrência do processo produtivo, a queima de combustíveis, entre inúmeras outras.

A raça humana habita o planeta há cerca de 2.5 milhões de anos, conforme estudos indicam, e, por motivos óbvios, desde os primórdios extrai sua subsistência do meio onde está inserida, da natureza (alimentos, moradia, vestuário, ferramentas, etc.). Sempre foi assim, desde os primitivos tempos em que o ser humano era um mero caçador-coletor (vivendo de pequenas presas e dos restos que encontrava na natureza) até os dias atuais (HARARI, 2015). Durante centenas de milênios a raça humana viveu de forma nômade e em plena harmonia com os recursos oferecidos pela natureza (até porque era como mais um simples animal em meio aos demais, sem o domínio exercido nos dias atuais), acontece que alguns fatores, como o surgimento da espécie sapiens (há cerca de 200.000 - duzentos mil anos), o crescimento exponencial da população humana, a revolução agrícola (há cerca de 70.000 - setenta mil anos) e também a mais recente revolução industrial (há cerca de 500 - quinhentos anos), acabaram por desequilibrar a simbiose outrora existente entre o ser humano e o meio ambiente.

Neste sentido, o reconhecimento da necessidade em se preservar o meio ambiente, surgiu principalmente do pensamento de que, desde os primórdios, o ser humano utiliza-se da natureza como instrumento e recurso inesgotável para suprir as suas necessidades de sobrevivência, assim, é de suma importância que o homem, utilizando-se de sua inteligência que the é inerente, vê-se na necessidade de preservar o meio ambiente, mantendo-o sadio e ecologicamente equilibrado para a atual e futura geração (LIMA et al., 2011).

Assim, em outras palavras, a raça humana, que outrora vivia em harmonia com os recursos oferecidos pelo planeta, avançou de tal maneira e em tantos aspectos que, para o suprimento de suas necessidades (cada vez mais crescentes e de diversas ordens), aumenta também a cada dia a exploração dos recursos naturais à sua disposição na natureza. Sobre a relação do homem com a natureza, Silva (2013) já afirma que a interação do homem com a natureza é paradoxal, uma vez que o homem, ao mesmo tempo em que é um animal que faz parte e integra a natureza, é extremamente dependente dela. Contudo, a ação antrópica passa a transformar a dinâmica natural do meio ambiente em maior intensidade, como um ser social e científico, colocando em risco a existência da natureza e, por consequência lógica, a sua.

Em determinado momento histórico foi sentida a necessidade de regulamentação da atuação humana sobre a natureza, com o fito de permitir a manutenção de um ambiente que permita a existência digna das gerações futuras (não somente humanas). A necessidade de regulamentação sobre o meio ambiente está marcada pela busca da compatibilidade entre o desenvolvimento econômico e proteção da 
natureza, em todas as suas formas. A visão de que o progresso somente seria alcançado com a destruição da natureza ocasionou a degradação ambiental em florestas, rios, qualidade do ar, dentre outras (BALCESKIS, 2015). A evolução social cumulada às complexas e crescentes necessidades da raça humana acabam por elevar de forma cada vez mais significativa a exploração ao meio ambiente onde está inserida. Surge então o Direito Ambiental, composto por princípios e regras, como instrumento regulador da atuação humana sobre o meio ambiente (ANTUNES, 2008), sendo ramo da ciência jurídica composto por normas (princípios e regras) voltados para a promoção de um desenvolvimento sustentável, ou seja, permitir a evolução social em seus mais diversos aspectos sem, no entanto, prejudicar a existência das gerações futuras.

No ordenamento pátrio existem importantes normas federais cujo objeto é a regulamentação da atuação humana sobre o meio ambiente, tais como a Lei 6.938, de 31/08/1981, que criou a Política Nacional do Meio Ambiente, a Lei 7.347, de 24/07/1985 (que disciplinou a Ação Civil Pública), a Constituição da República Federativa do Brasil de 1988 (que possui importante abordagem ambiental, diferente das constituições anteriores), a Lei 9.605, de 12/02/1998 (que tipifica os crimes ambientais), entre outras regras.

É mister, entretanto, considerar que toda lei possui forte carga valorativa a ela subjacente, ou seja, o fruto do processo legislativo deve obedecer aos mandamentos axiológicos representativos da sociedade onde será vigente. Tais valores, mandamentos nucleares de um sistema jurídico, são os princípios inerentes a cada ramo do Direito.

Assim, não basta apenas a aplicação das normas vigentes para uma adequada compatibilização da atividade humana sobre o meio ambiente, mas devem ser utilizadas pelos tribunais em consonância com a carga valorativa a elas subjacente. Isto porque a aplicação das normas de proteção ao meio ambiente deve refletir a carga valorativa inerente a elas, representada pelos princípios informativos do Direito Ambiental, por isso tão importante o conhecimento da aplicação pelo Tribunal Mineiro de tais mandamentos nucleares.

Assim o objetivo geral deste trabalho é verificar de maneira Verificar de maneira quantitativa a utilização da matriz principiológica do Direito Ambiental pelo Tribunal de Justiça de Minas Gerais (TJMG) dos princípios inerentes ao Direito Ambiental, com o fito de verificar os valores mais ínsitos na jurisprudência do Tribunal Mineiro, nos anos de 2014, 2015, 2016, 2017 e 2018, para a solução das demandas inerentes ao meio ambiente, e também quais ainda não ingressaram nas fundamentações jurídicas. Verificando assim os princípios inerentes ao direito Ambiental mais recorrentes na doutrina, analisando de maneira individual a aplicação de cada um dos princípios mais recorrentes na doutrina ambientalista pelo Tribunal de Justiça de Minas Gerais em seus julgamentos

\section{MATERIAIS E MÉTODOS}

Foi realizada pesquisa na doutrina especializada em Direito Ambiental para identificar os princípios mais recorrentes no Tribunal de Justiça de Minas Gerais. Após a seleção dos princípios objeto da pesquisa, o objetivo é verificar a citação pelo Tribunal de Justiça de Minas Gerais a cada um deles, para entender quais os valores ambientais norteiam sua jurisprudência. Assim, foi acessado o site virtual do Tribunal de Justiça 
de Minas Gerais ${ }^{1}$, onde há a disponibilização de elaborado sistema de busca e filtragem dos julgamentos ${ }^{2}$.

O mencionado sistema de pesquisa jurisprudencial permite ao usuário realizar buscas utilizando-se dos mais diversos critérios, tais como: número do processo, palavras chave, assunto, órgão julgador, relator responsável e tipo de recurso. Pode-se ainda limitar a pesquisa a órgãos julgadores específicos, período temporal determinado, etc.. Ato contínuo, utilizando do mencionado sistema de busca, foi realizada pesquisa quantitativa sobre quantas vezes o TJMG utilizou cada um dos princípios acima nos anos de 2014, 2015, 2016, 2017 e 2018.

O passo a passo para a realização da pesquisa obedeceu a seguinte ordem: 1 - Acessar ao site do $\mathrm{TJMG}^{3} ; 2$ - Na aba 'profissionais do direito', selecionar o item jurisprudência; 3 - Em seguida, dentre as opções disponíveis, selecionar a opção 'consulta de jurisprudência; 4 - Ato contínuo, selecionar 'acórdãos'; 5 Prosseguindo, escolher a opção 'consulte o sistema de acórdãos'; 6 - Clicar em 'sim' quando o navegador informar que irá continuar em uma nova página; 7 - Neste momento irá abrir a tela de busca ${ }^{4} ; 8$ - Tela de busca do site do TJMG, onde serão escolhidos os critérios da pesquisa; 9 - Em seguida, no campo palavras, inserir cada princípio entre aspas, um de cada vez, claro. Mister frisar que alguns princípios, por terem denominações genéricas ou nomenclatura similar a princípios de outros ramos do Direito, foram acompanhados pela expressão 'direito ambiental', para que a pesquisa abrangesse apenas suas menções no âmbito das demandas inerentes ao meio ambiente. Tal técnica foi utilizada com os seguintes princípios: solidariedade intergeracional, desenvolvimento sustentável, prevenção, precaução e cooperação; 10 Prosseguindo, Escolher a opção 'inteiro teor'; 11 - Não selecionar órgão julgador específico (pois o objeto é a análise do TJMG como um todo, não de câmaras específicas); 12 - Não selecionar relator específico (pois o objeto é a análise do TJMG como um todo, não de relatores específicos); 13 - Deixar em branco o campo 'Data de publicação'; No campo 'Data do julgamento' filtrar a pesquisa entre os dias 01/01 a 31/12 de cada um dos anos objeto da pesquisa $(2014,2015,2016,2017$ a 2018) (para permitir a comparação à menção do tribunal a cada princípio com o passar do tempo). Repetir a operação para todos os princípios pesquisados; 14 - Não escolher referência legislativa; 15 - Clicar em 'pesquisar'.

Após a pesquisa pela menção aos princípios, será possível criar um panorama de atuação do TJMG durante os últimos cinco anos, podendo-se extrair quais os valores são mais considerados quando da solução de demandas.

\section{RESULTADOS E DISCUSSÃO}

Os resultados obtidos pela pesquisa jurisprudencial realizada no site do TJMG - Tribunal de Justiça de Minas Gerais - permitem diversas conclusões acerca da utilização do panorama principiológico do Direito Ambiental em seus julgamentos. A título de exemplo, a pesquisa permite concluir algumas situações como: o aumento ou diminuição da menção a princípios no decorrer dos anos, qual princípio encontra-se de

\footnotetext{
${ }^{1}$ www.tjmg.jus.br

2 www5.tjmg.jus.br/jurisprudencia/

${ }^{3}$ www.tjmg.jus.br

${ }^{4}$ www5.tjmg.jus.br/jurisprudencia/
} 
maneira mais significativa presente no Tribunal Mineiro, quais princípios ainda encontram pouca aplicação, o histórico de menção de cada princípio no decorrer dos anos, entre outras circunstâncias. A análise do quadro 1 evidencia os resultados encontrados pela pesquisa.

Quadro 1: Números de citações a princípios inerentes ao direito ambiental utilizados pelo Tribunal de Justiça de Minas Gerais dos anos de 2014 a 2018.

\begin{tabular}{|c|c|c|c|c|c|c|}
\hline Princípio & 2014 & 2015 & 2016 & 2017 & 2018 & Total \\
\hline Princípio do meio ambiente ecologicamente equilibrado & 241 & 227 & 261 & 278 & 283 & 1290 \\
\hline Prevenção & 110 & 95 & 104 & 122 & 102 & 533 \\
\hline Precaução & 52 & 70 & 73 & 78 & 80 & 353 \\
\hline Desenvolvimento sustentável & 60 & 56 & 70 & 62 & 54 & 302 \\
\hline Poluidor-pagador & 31 & 62 & 65 & 69 & 60 & 287 \\
\hline Vedação ao retrocesso ambiental & 30 & 28 & 36 & 19 & 10 & 123 \\
\hline Cooperação & 8 & 13 & 20 & 15 & 15 & 71 \\
\hline Função sócio ambiental da propriedade & 6 & 4 & 12 & 9 & 5 & 36 \\
\hline Usuário-pagador & 0 & 3 & 2 & 4 & 6 & 15 \\
\hline Solidariedade intergeracional & 1 & 0 & 0 & 0 & 1 & 2 \\
\hline Controle do poluidor pelo poder público & 1 & 1 & 0 & 0 & 0 & 2 \\
\hline Protetor-recebedor & 0 & 0 & 0 & 0 & 0 & 0 \\
\hline $\begin{array}{l}\text { Consideração da variável ambiental no processo decisório de políticas de } \\
\text { desenvolvimento }\end{array}$ & 0 & 0 & 0 & 0 & 0 & 0 \\
\hline Citações a princípios em cada ano: & 540 & 559 & 643 & 656 & 616 & 3014 \\
\hline
\end{tabular}

Entre os anos de 2014 e 2018 os princípios objeto da pesquisa totalizaram aparições em 3014 (três mil e quatorze) julgamentos, o que deixa em evidência a fundamentação axiológica constantemente utilizada pelo Tribunal de Justiça de Minas Gerais.

\section{Princípio do meio ambiente ecologicamente equilibrado}

Sobre o meio ambiente ecologicamente equilibrado são válidos os ensinamentos de Goulart et al. (2012), que afirmam que tal direito emana da proteção contra qualquer privação despótica da vida, mas também do fato de que, nos tempos de agora, o Estado está compelido a encontrar diretrizes capazes de garantir o acesso aos meios de sobrevivência da humanidade como um todo. Logo, com espeque em tal fundamento, o Estado tem o dever de fazer evitar a ocorrência de riscos ambientais prejudiciais à própria vida.

Assim, conforme ensina Ferreira (1995), a Constituição de 1988, ao estipular o meio ambiente ecologicamente equilibrado, princípio jurídico expresso em sua redação, passou a nortear toda legislação subjacente, e a dar uma nova conotação a todas as leis em vigor, no sentido de favorecer uma interpretação coerente com a orientação político-institucional então inaugurada. Sobre o princípio do meio ambiente ecologicamente equilibrado, é possível perceber o aumento de sua utilização pelo TJMG com o decorrer dos anos, conforme figura 1.

Entre os anos de 2014 e 2018 é possível verificar um aumento de 17,42\% nas decisões proferidas pelo TJMG em que o princípio do meio ambiente ecologicamente equilibrado se fez presente. Se a comparação for entre os anos de 2015 e 2018 o aumento é ainda mais considerável, de 24,66\%. Tal circunstância evidencia a clara tendência de aumento de utilização do princípio do meio ambiente ecologicamente equilibrado como fundamento de decisões pelo TJMG. 


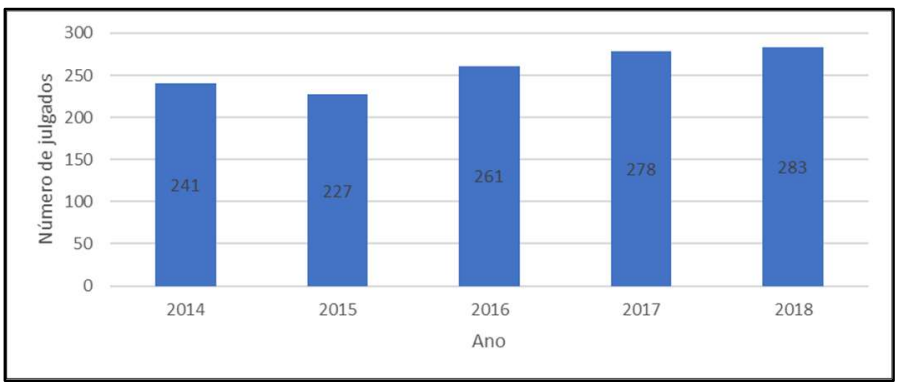

Figura 1: Evolução do princípio do meio ambiente ecologicamente equilibrado entre os anos de 2014 e 2018 para o Tribunal de Justiça de Minas Gerais.

\section{Princípio da Prevenção e Precaução}

O verbo prevenir tem sua origem etimológica na junção de duas palavras em latim, quais sejam, prae (antes) + venire (vir, chegar), ou seja, traduz a ideia de chegar antes, de antecipação a algo conhecido. Já a palavra precaução é substantivo de o verbo precaver, cuja origem etimológica pode ser encontrada na junção de duas palavras em latim, quais sejam, prae (antes) + cavere (tomar cuidado, acautelar-se), ou seja, traduz a ideia de tomar cautela em relação ao desconhecido.

No âmbito do Direito Ambiental o princípio da prevenção está relacionado com os riscos previamente conhecidos pela ciência em razão da atividade praticada e que deverão, sempre que possível, ser evitados ou mitigados. Deve-se, desta forma, haver a antecipação do poder público e da coletividade a potenciais riscos de dano previamente conhecidos. Preferencialmente o dano deve ser prevenido. A reparação do dano causado deve ser situação excepcional, em especial levando-se em consideração que muitas vezes são irreversíveis e irreparáveis.

O princípio da prevenção, aplica-se ao risco conhecido. Esse risco é entendido como aquele identificado por meio de pesquisas, dados e informações ambientais ou porque já ocorreu anteriormente. É a partir desse risco ou perigo conhecido que se busca a adoção de medidas para impedir ou minimizar que ocorram danos ao meio ambiente (CIELO et al., 2012). Observa-se que alguns dos princípios objeto da pesquisa tiveram queda em sua incidência na jurisprudência do Tribunal de Justiça de Minas Gerais, serão analisados a seguir na figura 2. De início, merece atenção o princípio da prevenção.

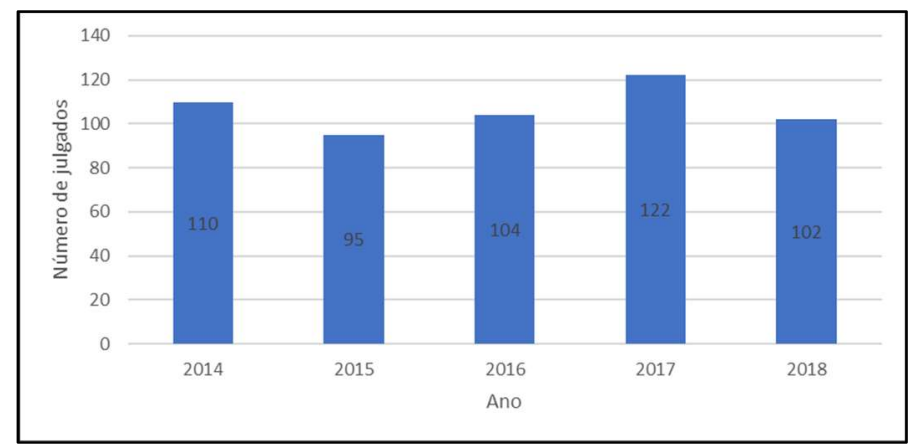

Figura 2: Evolução do princípio da prevenção entre os anos de 2014 e 2018 para o Tribunal de Justiça de Minas Gerais.

Observa-se na figura 2 que em 2014 o princípio da prevenção foi mencionado pelo Tribunal Mineiro em 110 (cento e dez) julgamentos, enquanto em 2018 esteve presente em 102 (cento e dois) julgados, ou seja, uma redução de $7,27 \%$. 
Muito embora de 2014 a 2018 tenha havido uma leve redução no número de demandas (110, em 2014, e 102, em 2018) onde há menção ao princípio da prevenção, durante o passar dos anos sua utilização tem ficado estável. Ademais, conforme já mencionado acima, a incidência do princípio da precaução experimentou considerável aumento, o que pode representar que o Tribunal Mineiro tem utilizado ambos de maneira indiscriminada e sem grande precisão terminológica.

Há uma importante distinção, perceba. O princípio da prevenção está relacionado aos riscos já conhecidos pela ciência, sua marca é a certeza, enquanto a precaução vincula-se a riscos desconhecidos, a situações de incerteza.

O princípio em apreço foi expressamente consagrado pela Declaração do Rio de Janeiro na Conferência das Nações Unidas sobre Meio Ambiente e Desenvolvimento (RIO DE JANEIRO, 1992), em seu princípio de número 15, que segue para melhor ilustrar: Princípio 15: Com o fim de proteger o meio ambiente, o princípio da precaução deverá ser amplamente observado pelos Estados, de acordo com suas capacidades. Quando houver ameaça de danos graves ou irreversíveis, a ausência de certeza científica absoluta não será utilizada como razão para o adiamento de medidas economicamente viáveis para prevenir a degradação ambiental.

Milaré (2015) esclarece acerca do princípio em questão que tal princípio enfrenta a incerteza dos saberes científicos em si mesmos. Sua aplicação observa argumentos de ordem hipotética, situados no campo das possibilidades, e não de posicionamentos científicos claros e conclusivos. Procura instituir procedimentos capazes de embasar uma decisão racional na fase de incertezas e controvérsias, de forma a diminuir os custos da experimentação. É recorrente sua invocação, por exemplo, quando se discutem questões como o aquecimento global, a engenharia genética e os organismos geneticamente modificados, a clonagem, a exposição a campos eletromagnéticos gerados por estações de radiobase.

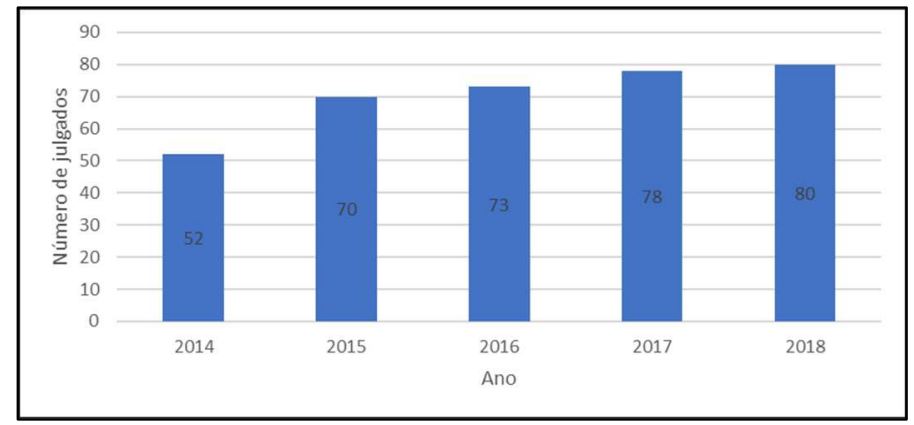

Figura 3: Evolução do princípio da precaução entre os anos de 2014 e 2018 para o Tribunal de Justiça de Minas Gerais.

O princípio da precaução parece estar cada vez mais presente no Tribunal de Justiça de Minas Gerais, em especial levando-se em consideração sua evolução percentual entre 2014 e 2018, que foi de 53,84\%. Tal circunstância demonstra a crescente preocupação do Tribunal Mineiro com os riscos de danos ambientais inicialmente desconhecidos, buscando mitigar os perigos de eventuais incertezas científicas. Interessante observar que desde 2014 verificou-se aumento na utilização do princípio da precaução em todos os anos objeto da pesquisa. De 2014 para 2015 o incremento foi de 34,61\%; de 2015 para 2016 houve acréscimo de 4,28\%; de 2016 para 2017, de 6,84\%; de 2017 para 2018, de 2,56\%. 


\section{Princípio do Desenvolvimento sustentável}

O princípio busca compatibilizar o desenvolvimento da sociedade com a preservação do meio ambiente, sem que sua exploração cesse, posto ser necessária para a manutenção da vida humana. Conforme define Fiorillo et al. (2017), o princípio possui grande importância, porquanto numa sociedade desregrada, à deriva de parâmetros de livre concorrência e iniciativa, o caminho inexorável para o caos ambiental é uma certeza. Não há dúvida de que o desenvolvimento econômico também é um valor precioso da sociedade. Todavia, a preservação ambiental e o desenvolvimento econômico devem coexistir, de modo que aquela não acarrete a anulação deste.

Canotilho (2010) também aborda a questão da sustentabilidade afirmando que o princípio da sustentabilidade aponta para a necessidade de novos esquemas de direção propiciadores de um verdadeiro Estado de direito ambiental. Isto implica que, ao lado dos tradicionais esquemas de ordem, permissão e proibição vasados em atos de poder público, se assista ao recurso a diversas formas de 'estímulo' destinadas a promover programas de sustentabilidade (exemplo: política fiscal de incentivo a tecnologia limpa, estímulo para a efetivação de políticas de energia à base de recursos renováveis). Nestes 'estímulos' ou 'incentivos' que, muitas vezes, se traduzem em preferências ou internalizações de efeitos externos, devem se observar as exigências normativas do Estado de direito ambiental quanto às competências (legislador e executivo) e aos princípios (proibição do excesso, igualdade). Também, pode-se perceber decréscimo na citação ao princípio do desenvolvimento sustentável, conforme resta demonstrado pela figura 4.

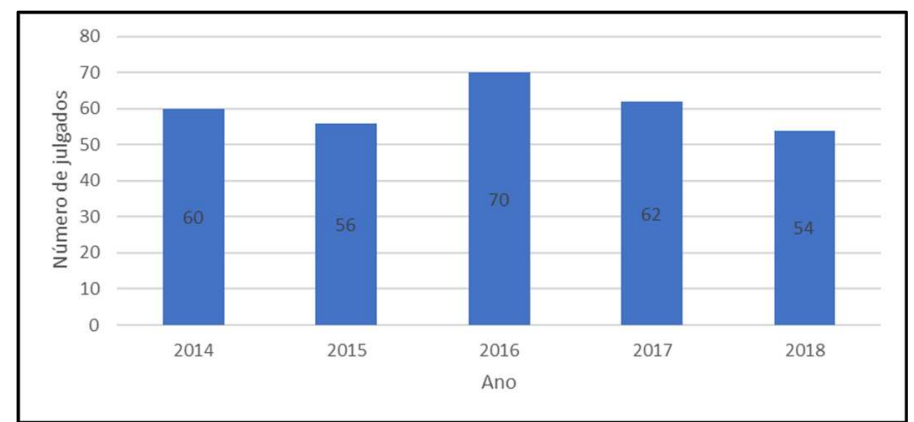

Figura 4: Evolução do princípio do desenvolvimento sustentável entre os anos de 2014 e 2018 para o Tribunal de Justiça de Minas Gerais.

Na comparação direta entre os anos de 2014 e 2018, assim como o princípio da prevenção, o do desenvolvimento sustentável também experimentou decréscimo nas aparições em julgados do TJMG, mas manteve certa estabilidade durante o passar dos anos.

\section{Princípio do Poluidor-Pagador}

O princípio do poluidor-pagador pode ser entendido como sendo um instrumento econômico e também ambiental, que exige do poluidor, uma vez identificado, suportar os custos das medidas preventivas e/ou das medidas cabíveis para, senão a eliminação pelo menos a neutralização dos danos ambientais (COLOMBO, 2004).

As autoridades nacionais devem procurar promover a internacionalização dos custos ambientais e o 
uso de instrumentos econômicos, tendo em vista a abordagem segundo a qual o poluidor deve, em princípio, arcar com o custo da poluição, com a devida atenção ao interesse público e sem provocar distorções no comércio e nos investimentos internacionais.

É importante frisar que 'arcar com os custos da poluição' é expressão ampla, que abrange não somente a reparação por eventuais danos causados, mas também, por óbvio o custeio das medidas preventivas (princípio da prevenção) e também acautelatórias (princípio da precaução). De bom alvitre são as palavras de Fiorillo et al. (2017), que afirma que, num primeiro momento, impõe-se ao poluidor o dever de arcar com as despesas de prevenção dos danos ao meio ambiente que sua atividade possa ocasionar. Cabe a ele o ônus de utilizar os instrumentos necessários à prevenção dos danos. Em uma segunda órbita de alcance, esclarece este princípio que, ocorrendo danos ao meio ambiente em razão da atividade desenvolvida, o poluidor será responsável pela sua reparação.

O ordenamento pátrio, atendendo ao comando do princípio do poluidor-pagador, possui diversos instrumentos para sua consecução, tanto na Constituição de 1988, quanto na legislação infraconstitucional. Também com considerável evolução, é o princípio do poluidor-pagador na figura 5.

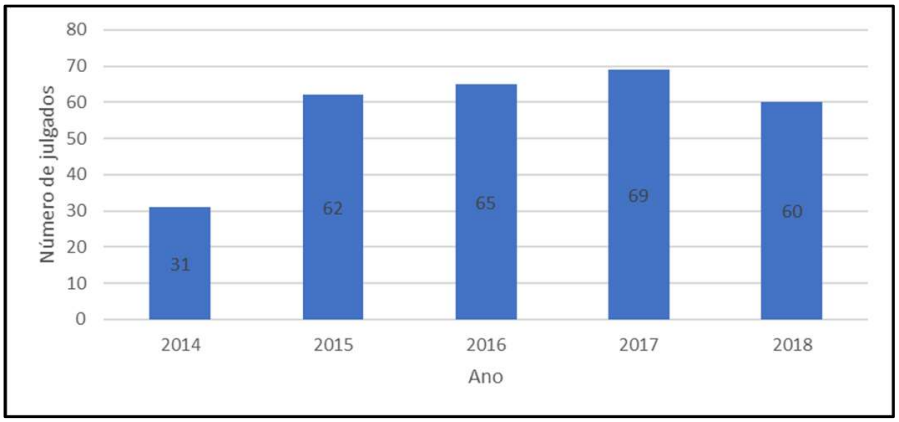

Figura 5: Evolução do princípio do poluidor-pagador entre os anos de 2014 e 2018 para o Tribunal de Justiça de Minas Gerais.

O ápice de sua menção em decisões do TJMG foi no ano de 2017, com 69 (sessenta e nove) aparições, entretanto, desde 2014 apresenta um aumento de 93,54\%, ou seja, sua utilização quase dobrou. Esse aumento de incidência do princípio do poluidor-pagador evidencia a preocupação do Tribunal de Minas Gerais em fundamentar também sob o viés principiológico as condenações de reparação àqueles que causam danos ao meio ambiente.

Com a aplicação do Princípio do Poluidor-Pagador, reitera-se que o fim precípuo do Direito Ambiental, a prevenção dos danos ao meio ambiente, está presente, ainda que com menos intensidade, no princípio anteriormente mencionado, o que coaduna com as exigências da tutela dos direitos difusos e coletivos, reconhecidos constitucionalmente e amplamente discutidos em nossa sociedade (COLOMBO, 2004).

\section{Princípio da Vedação ao retrocesso ambiental}

Chama a atenção a redução à menção pelo Tribunal de Minas ao princípio da vedação ao retrocesso ambiental, conforme pode-se perceber abaixo na figura 6 . 


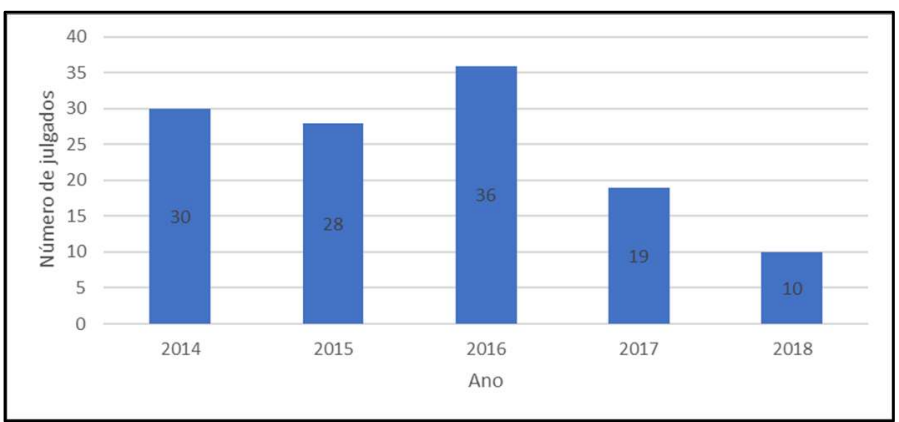

Figura 62: Evolução do princípio da vedação ao retrocesso ambiental entre os anos de 2014 e 2018 para o Tribunal de Justiça de Minas Gerais.

A redução é de aproximadamente $66,66 \%$ na utilização pelo TJMG do princípio da vedação ao retrocesso ambiental. Num olhar inicial o contexto pode parecer preocupante, posto ser relativo a importante valor de proteção ao meio ambiente, mas numa análise mais ampla essa redução não implica de forma necessária numa menor proteção, em especial porque num contexto geral houve considerável aumento na utilização principiológica. Ademais, o Tribunal continua utilizando-se da malha legislativa para a tutela ambiental.

O que se busca com o princípio da vedação ao retrocesso é proibir que garantias constitucionais ou legais voltadas para a esfera ambiental sejam suprimidas em prol de interesses outros, colocando-se a manutenção do equilíbrio ambiental em segundo plano, o que, como consectário lógico, colocaria em risco as futuras gerações. Conforme palavras de Benjamin (2012), o princípio da proibição de retrocesso, sobretudo quanto ao chamado núcleo legislativo duro do arcabouço do Direito Ambiental, isto é, os direitos e instrumentos diretamente associados a manutenção do "meio ambiente ecologicamente equilibrado" e dos "processos ecológicos essenciais", plasmados no art. 225 da Constituição de 1988.

A proibição de retrocesso, nesse cenário, diz respeito mais especificamente a uma garantia de proteção dos direitos fundamentais (e da própria dignidade da pessoa humana) contra a atuação do legislador, tanto no âmbito constitucional quanto - e de modo especial - infraconstitucional (quando estão em causa medidas legislativas que impliquem supressão ou restrição no plano das garantias e dos níveis de tutela dos direitos já existentes), mas também proteção em face da atuação da administração pública (SARLET, 2011).

\section{Princípio da Cooperação}

O princípio recebe diversas denominações na doutrina, tais como participação, participação comunitária e, claro, cooperação. Mas se referem à mesma norma. Traduz a ideia de que a solução das demandas ambientais deve acontecer por meio de cooperação entre poder público e a sociedade, não sendo de responsabilidade exclusiva de um ou outro. Muito embora os princípios não precisem estar necessariamente expressos na lei, a doutrina em geral extrai a cooperação do texto da Constituição de 1988, quando impõe tanto ao Poder Público quanto à coletividade o dever de defendê-lo e preservá-lo (GRANZIERA, 2009). A evolução da aplicação do princípio da cooperação para o Tribunal de Justiça de Minas Gerais pode ser observada na figura 7. Desde 2014 é possível perceber que sua presença em decisões do 
Tribunal cresceu $87,5 \%$.

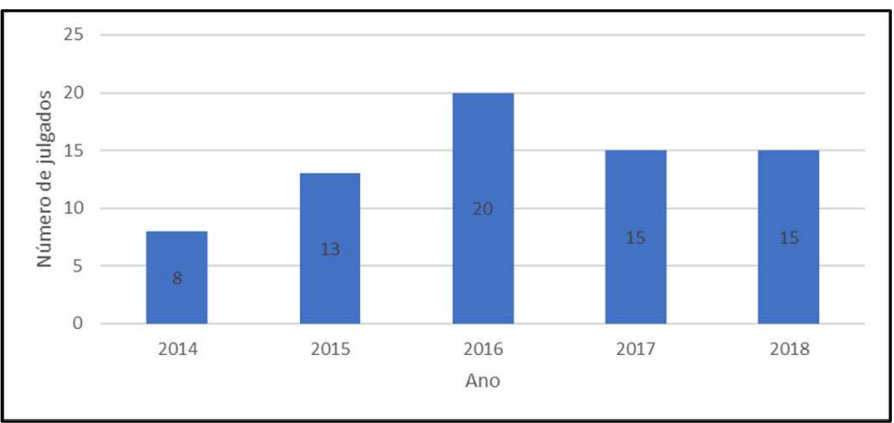

Figura 7: Evolução do princípio da cooperação entre os anos de 2014 e 2018 para o Tribunal de Justiça de Minas Gerais.

\section{Princípio da Função Sócio Ambiental da Propriedade}

A função socioambiental da propriedade, funcionaliza o exercício do direito de propriedade a interesses extra proprietários, como a preservação do meio ambiente, consoante o que dispõe o caput do artigo 1.228 do Código Civil.

A propriedade tende a traduzir uma relação entre sujeito e bem cujo exercício em prol da sociedade apresenta interesse público relevante, traduzindo um direito-meio, e não um direito-fim, não sendo garantia em si mesma, só se justificando como instrumento de viabilização de valores fundamentais, dentre os quais sobressai o da dignidade da pessoa humana (DERANI, 2002). Prosseguindo, segue análise do princípio da função socioambiental da propriedade, figura 8.

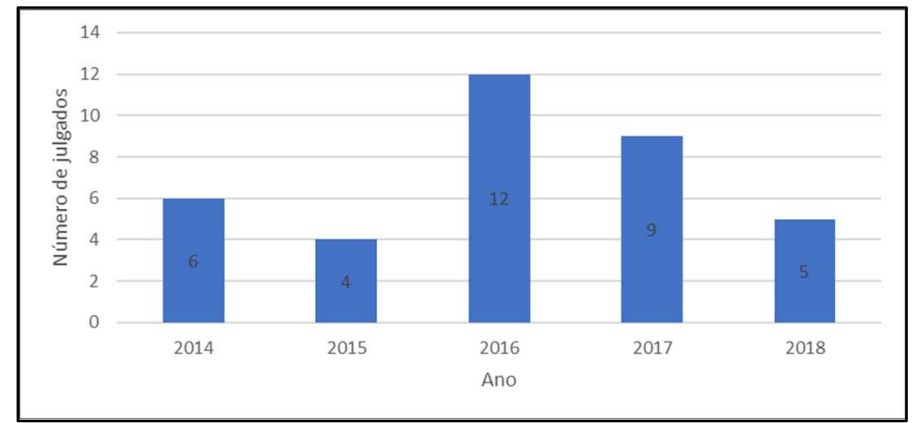

Figura 8: Evolução do princípio da função socioambiental da propriedade entre os anos de 2014 e 2018 para o Tribunal de Justiça de Minas Gerais.

Princípio de pouca incidência na jurisprudência do Tribunal de Minas, circunstância que pode ser explicada por sua próxima relação com o princípio da função social da propriedade, inerente ao Direito Civil (a função social abrange também a obrigatoriedade de o proprietário respeitar o meio ambiente). Houve redução de $16,6 \%$, o que equivale a apenas uma citação a menos em julgamentos.

A expressão função social passa por uma ideia operacional, impondo ao proprietário não somente condutas negativas (abstenção, como não causar contaminação do solo), mas também positivas (obrigações de fazer, como de parcelar gleba de sua propriedade) (MIRRA, 1996).

\section{Princípio do Usuário-Pagador}

O princípio do usuário pagador está expresso na Lei no 9.433, de 08 de janeiro de 1997 que prevê 
que os recursos ambientais são escassos (art. 1) e que, aquele que os utiliza mais, em detrimento dos demais, deve arcar com o correlativo ônus pelo seu uso intensivo (BRASIL, 1997).

Questões como o custo do uso dos recursos naturais, a plena reparabilidade dos danos ambientais, o direito ao meio ambiente saudável das gerações futuras, a equidade intergeracional, o objeto a ser preservado nos diversos ecossistemas, toda essa complexidade exige não só uma rigorosa definição do que seja a natureza e o gênero de direito a está associada, mas também o debate e a proposta de soluções concretas para esses impasses (MOTA, 2015). Segue na figura 9 os resultados do princípio usuário-pagador.

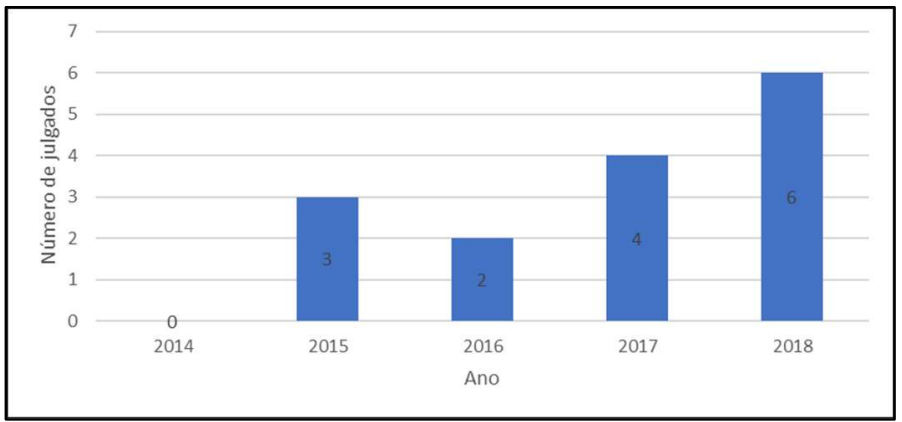

Figura 9: Evolução do princípio do usuário-pagador entre os anos de 2014 e 2018 para o Tribunal de Justiça de Minas Gerais.

Em relação ao princípio acima a análise fria dos números pode levar a equívoco quanto à sua utilização pelo TJMG, uma vez que de 2014 a 2018 houve evolução de 600\% em sua aparição em julgamentos. Todavia, o grande aumento percentual é justificado porque em 2014 o usuário-pagador não foi utilizado uma vez sequer, e, ao que parece, vem sendo inserido aos poucos na jurisprudência do Tribunal.

Princípio da solidariedade intergeracional e princípio do controle do poluidor pelo poder público, e demais princípios não citados

Agrupou-se os dois últimos princípios citados devido a sua pouca utilização pelo TJMG. A começar pelo princípio da solidariedade intergeracional, pode-se seus resultados pela figura 10.

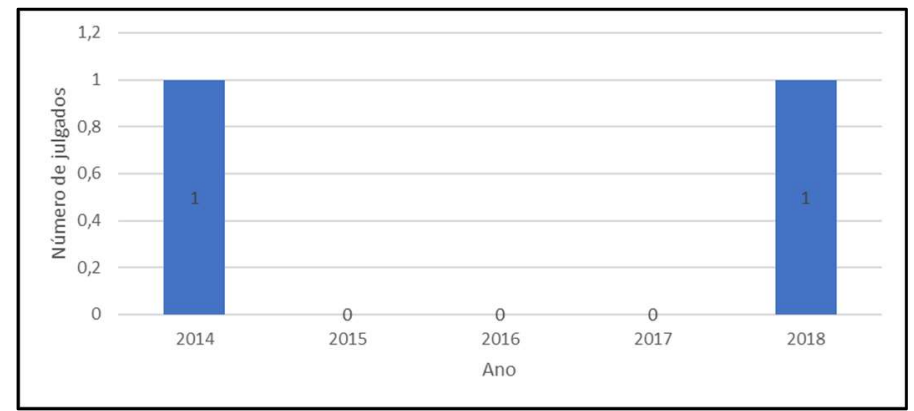

Figura 10: Evolução do princípio da solidariedade intergeracional entre os anos de 2014 e 2018 para o Tribunal de Justiça de Minas Gerais.

No ano de 2014 a solidariedade intergeracional foi mencionada apenas uma vez, não sendo sequer citada em 2015, 2016 e 2017, aparecendo novamente em 2018 com apenas uma menção. É interessante mencionar sua pouca incidência no TJMG não significa falta de preocupação com as próximas gerações, em especial porque todo panorama protetivo do meio ambiente visa a manutenção de um meio ambiente 
ecologicamente equilibrado para as futuras gerações. Também experimentou redução nas menções em decisões do TJMG o princípio do controle do poluidor pelo poder público.

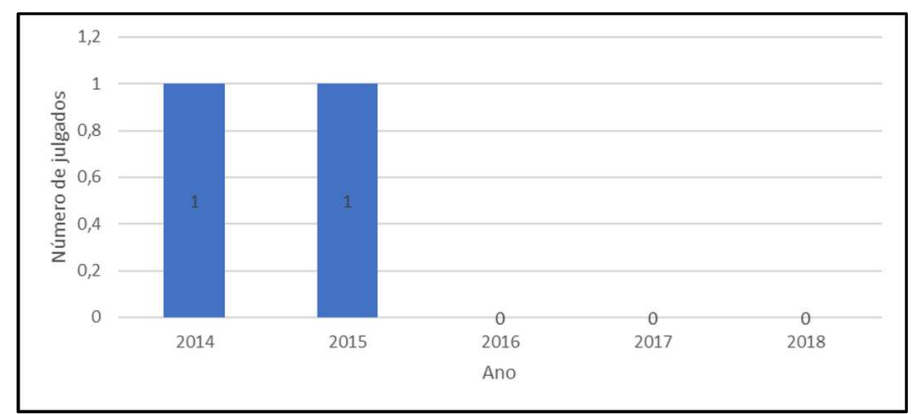

Figura 31: Evolução do princípio do controle do poluidor pelo poder público entre os anos de 2014 e 2018 para o Tribunal de Justiça de Minas Gerais.

Em 2014 e 2015 houve apenas uma citação em julgamentos realizados pelo TJMG, não sendo mais mencionados em 2016, 2017 e 2018. Evidente o fato de tal circunstância não significar ausência de controle dos poluidores pelo poder público, mas apenas que o princípio em tela. Há também princípios que não ingressaram na jurisprudência do Tribunal de Justiça de Minas Gerais, como o do protetor-recebedor e o da consideração da variável ambiental no processo decisório de políticas de desenvolvimento.

Sobre a indiferença do Tribunal Mineiro ao princípio do protetor-recebedor, é patente o fato de que a ideia de remunerar as boas práticas ambientais ainda não possui aplicabilidade em Minas Gerais, conforme já mencionado no corpo deste trabalho.

Quanto a ausência de menção ao princípio da consideração da variável ambiental no processo decisório de políticas de desenvolvimento é possível perceber se tratar de um princípio muito específico, que o tribunal pode até mencioná-lo utilizando-se de outras palavras ou expressões. Outro fator é que a observação pelo poder público em relação a políticas de desenvolvimento é realizada pelo Poder Executivo, não pelo judiciário.

\section{CONCLUSÕES}

A análise dos dados obtidos com a pesquisa realizada no bojo deste trabalho leva à importante conclusão de que ao tutelar o meio ambiente o Tribunal de Justiça de Minas Gerais não se utiliza apenas da legislação vigente sobre o tema, mas busca fundamentar suas decisões também no panorama principiológico inerente ao Direito Ambiental, de forma a evidenciar os valores que norteiam o julgamento de suas demandas. Entre os anos de 2014 e 2018 os princípios objeto da pesquisa totalizaram aparições em 3014 (três mil e quatorze) julgamentos, o que deixa em evidência a fundamentação axiológica constantemente utilizada pelo Tribunal de Justiça de Minas Gerais.

Os cinco princípios ambientais mais ínsitos na jurisprudência do Tribunal Mineiro são, na seguinte ordem: o meio ambiente ecologicamente equilibrado, presente em 1290 julgamentos; o da prevenção, presente em 533 julgamentos; o da precaução, presente em 353 julgamentos; o do desenvolvimento sustentável, presente em 302 julgamentos; e o poluidor-pagador, presente em 287 julgamentos. Lado outro, alguns princípios ainda não ingressaram na jurisprudência do Tribunal Mineiro, sendo eles: o protetor- 
recebedor e o da consideração da variável ambiental no processo decisório de políticas de desenvolvimento, ambos sem qualquer menção.

Os dados evidenciam também tendência de aumento na utilização de fundamentação axiológica pelo Tribunal Mineiro com o passar dos anos, circunstância verificável pelo aumento de 14,7\% na utilização de princípios inerentes ao Direito Ambiental nas decisões do Tribunal. Fica evidente então, a importância dos princípios não só no Direito Ambiental, mas como em qualquer ramo do Direito, uma vez que além de possuírem força normativa, representam os valores mais importantes de uma determinada sociedade, servindo de base para a compreensão das normas.

\section{REFERÊNCIAS}

BALCESKIS, A. C. C.. Direito ambiental: desenvolvimento sustentável e infraestrutura. FMU Direito Revista Eletrônica, v.28, n.42, 2015.

BENJAMIN, A. H.. Princípio da Proibição de Retrocesso Ambiental. Brasília, 2012.

BRASIL. Lei n. 9.433, de 8 de janeiro de 1997. Institui a Política Nacional de Recursos Hídricos, cria o Sistema Nacional de Gerenciamento de Recursos Hídricos, regulamenta o inciso XIX do art. 21 da Constituição Federal, e altera o art. 10 da Lei no 8.001, de 13 de março de 1990, que modificou a Lei no 7.990 , de 28 de dezembro de 1989. Brasília: DOU, 1997.

CANOTILHO, J. J. G.. O Princípio da sustentabilidade como Princípio estruturante do Direito Constitucional. TékhneRevista de Estudos Politécnicos, n.13, p.7-18, 2010.

CIELO, P. F. L. D.; SANTOS, F. R.; STACCIARINI, L. S.; SILVA, V. G.. Uma leitura dos princípios da prevenção e da precaução e seus reflexos no Direito Ambiental. Revista CEPPG, v.26, n.1, p.196-207, 2012.

COLOMBO, S.. Aspectos conceituais do princípio do poluidor-pagador. Revista Eletrônica do Mestrado em Educação Ambiental, v.13, 2004. DOI:

https://doi.org/10.14295/remea.v13i0.2720

ANTUNES, P. B.. Direito ambiental. Rio de Janeiro: Lumen Juris, 2008.

RIO DE JANEIRO. Conferência das Nações Unidas sobre Meio Ambiente e Desenvolvimento. Estud. Av., v.6, n.15, p.153159, 1992.

DERANI, C.. A propriedade na Constituição de 1988 e o conteúdo da 'função social'. Revista de Direito Ambiental, São Paulo, v.7, n.27, p.58-69, 2002.

FERREIRA, I. S.. Tutela penal do patrimônio cultural. 1995.
FIORILLO, C. A. P.; FERREIRA, R. M.. Curso de Direito Ambiental Brasileiro. 17 ed. São Paulo: Saraiva, 2017.

GOULART, L. H.; FERNANDES, J. L.. Direito à propriedade e ao meio ambiente ecologicamente equilibrado: a colisão de direitos fundamentais. Veredas do Direito: Direito

Ambiental e Desenvolvimento Sustentável, v.9, n.17, p.133, 2012.

GRANZIERA, M. L. M.. Direito ambiental. São Paulo: Atlas, 2009.

HARARI, Y. N.. Sapiens: uma breve história da humanidade. Porto Alegre: L\&PM, 2015.

LIMA, S. A.; MORAIS, C. K. T.; ALMEIDA, G. E. M.. Meio ambiente ecologicamente equilibrado: direito ambiental, fundamental e humano, dever social. Qualitas Revista Eletrônica, v.11, n.1, 2011.

MILARÉ, É.. Direito do ambiente. 10 ed. São Paulo: RT, 2015.

MIRRA, A. V.. Princípios fundamentais do Direito Ambiental. Revista de Direito Ambiental. São Paulo: RT, 1996.

MOTA, M.. A função socioambiental da propriedade: a compensação ambiental como decorrência do Princípio do usuário pagador. Revista de Direito da Cidade, v.7, n.2, p.776-803, 2015.

SARLET, I. W.; FENSTERSEIFER, T.. Notas sobre os deveres de proteção do estado e a garantia da proibição de retrocesso em matéria (sócio) ambiental. Caxias do Sul: Educs, 2011.

SILVA, R. Z.. Os desafios do direito ambiental no limiar do século XXI diante da ineficácia do sistema jurídico ambiental brasileiro. Veredas do Direito: Direito Ambiental e Desenvolvimento Sustentável, Belo Horizonte, v.9, n.18, p.57, 2013.

A CBPC - Companhia Brasileira de Produção Científica (CNPJ: 11.221.422/0001-03) detém os direitos materiais desta publicação. Os direitos referem-se à publicação do trabalho em qualquer parte do mundo, incluindo os direitos às renovações, expansões e disseminações da contribuição, bem como outros direitos subsidiários. Todos os trabalhos publicados eletronicamente poderão posteriormente ser publicados em coletâneas impressas sob coordenação da Sustenere Publishing, da Companhia Brasileira de Produção Científica e seus parceiros autorizados. Os (as) autores (as) preservam os direitos autorais, mas não têm permissão para a publicação da contribuição em outro meio, impresso ou digital, em português ou em tradução. 